\title{
Assessment of investment appeal of industrial enterprises
}

\author{
Mikhail Kuvshinov ${ }^{1, *}$, Anna Kalacheva ${ }^{1}$, and Andrey Butrin ${ }^{1}$ \\ ${ }^{1}$ South Ural State University (National Research University), the Department of Finance, Money Circulation and Credit, 454080 \\ Chelyabinsk, Russia
}

\begin{abstract}
Expansion of the completeness of examination of the investment appeal of the enterprises considering all set of interests of the specific investor in an integral indicator, and providing sufficiency of reliability represents an actual task. On the basis of refining of the concept "investment appeal of the enterprise" the economic-mathematical model of an assessment of investment appeal of industrial enterprises providing possibility of step-by-step selection of options of forming of its investment image at decrease in the risks decision making corresponding to interests of the specific investor is developed. Methodical approach, the implementing its algorithm and the software product at the choice of options of forming of investment image or a choice of investees with the subsequent assessment of attractive options and receipts of the aggregate result which is most corresponding to preferences of the specific investor is developed. The practical recommendations about a choice of acceptable ranges of change of critical parameters of an integral indicator for the recommended assessment model allowing to prove decisions on the accepted options on management of investment appeal of the enterprises or the chosen investees are developed.
\end{abstract}

\section{Introduction}

The real investments in industrial enterprises is one of the defining factors of development of the enterprises, regions and national economy in general. At the present stage industrial enterprises create $24 \%$ of GDP of Russia. Their further development in an essential measure depends on the size of the attracted real investments. In the current conditions of economy of Russia limitation of financial resources is observed and each enterprise interested in attraction of external sources for financing of the development needs to possess the sufficient level of investment appeal in view of the high competition of objects of the real investments in the market of investment resources Therefore analytically defined assessment of the current level of investment appeal at risk minimization of adoption of the wrong decision is required to two parties of investment process. First, to management of the enterprise for reasonable determination of a vector of further development of the enterprise for the purpose of improvement of its investment image. Secondly, investors for making decision on a choice of the enterprise recipient need to estimate a condition of the applicant enterprises, perspectives of their development taking into account all concurrent factors, essential to them.

\section{Relevance and scientific importance}

Different approaches to an assessment of investment appeal of industrial enterprises, known at the moment in economic practice, or have restrictions by quantity of the considered factors and indicators characterizing them, or demand availability of big arrays of initial information which not always is available, or do not consider interests of specific investors concerning the importance of separate factors and indicators, or are very labourconsuming $[1,2,3,4,5,6,7,8$, etc. $]$.

In a similar situation there is a problem of expansion of completeness of examination of investment appeal of the enterprises on the basis of the complex assessment reflecting and considering all set of the corresponding preferences and interests of the specific investor in an integral indicator, and providing sufficiency of reliability of such examination.

As investment objects foreign and domestic economists at different times were engaged in research of questions of the theory of the investment analysis, attractiveness of the enterprises [2, 4, 7, 9, 10, 11, etc.]. At the same time, despite considerable achievements in the field, did not find due reflection and the questions connected with an integral assessment of the current level of investment appeal at a choice of potential options of development of the enterprise and forming of its attractive investment image demand further research.

*Corresponding author: msk1954@mail.ru 
Similar questions arise and at investors recipients at a choice of potential objects of the real investments.

\section{Problem definition}

The created assessment of investment appeal of industrial enterprises in view of large volumes and complexity of accounting of interrelations of the used indicators has to exclude processing of redundant information and be carried out in full accordance with interests of the specific investor on the importance of separate factors or indicators. Therefore the methodical tools allowing on a limited set of indicators criteria, critical for the specific investor are required to choose to select from a large number of potential options of development of the enterprise and forming of its investment image or from potential investees significantly smaller group for which then to make more detailed analysis of investment appeal, excepting the options which are obviously unattractive for the investor. Increase of reliability of examination reduces risks at a variable choice of option of forming of investment image of the enterprise or a choice of an investee. The specified problem of a reasonable choice exists for the majority of the enterprises of real production sector, and its decision allows to create attractive investment image and to avoid probable essential economic losses for investors.

The analysis of different approaches to determination of the concept "investment appeal of the enterprise" showed absence of unity in the matter. Thus the existing approaches do not consider or a risk component of investment appeal, or influence of diverse factors, significant for the investor (internal and external, quantitative and qualitative), or only the economic result of investment is taken into account.

\section{Theoretical part}

Authors offer the specified determination of concept investment appeal of the enterprise is the complex characteristic of the enterprise forming under the influence of all factors, significant for potential external investors, internal and external environment and providing information on capability of the enterprise to provide as a result of the activity the indicators demanded on structure and size (economic, social, etc.) at acceptable risk level. This determination allows to take into account variety of internal and external factors of forming of the assessment performed always from a position of requirements of specific investors taking into account an effect ratio, including non-economic, and risk of investment.

The assessment of investment appeal of the enterprise has to consider in a complex all differentiation of requirements of investors to effect and risks of investment. For an assessment of required effect it is necessary to enter the quantitative criterion including an assessment of the economic, social and/or other effect essential to specific users of this information. Rather investment risk it is similarly necessary to define a complex quantitative assessment of the financial, material and/or other risks essential to specific users. Use of separate quantitative indices of effect and risk allows to consider information, most essential to any investor, at an assessment of investment appeal of the enterprise: about return of option of capital investments and about the level of neigh boring risks (for capital repayment, achievement of expected return). In model the result answering to preferences of the specific investor allows to have an opportunity of regulation of the importance of these indicators.

On the basis of the analysis of merits and demerits of known models of an assessment of investment appeal of the enterprises the author's model which represents set of the connected dependences allowing to estimate investment appeal on the basis of the integral $Y 0$ indicator created based on two group indicators is offered: investment potential of $X_{I P}$ enterprise and factors of its investment risks of $\mathrm{X}_{I R}$ by means of linear factor model with weight coefficients of $C_{1 k}$ :

$$
Y_{0}=C_{1 I P} X_{I P}+C_{1 I R} X_{I R}
$$

Investment potential is understood as ensuring the required effect answering the investor's purpose. Authors suggest an indicator of investment potential of the enterprise to create on the basis of the complex estimates of separate structural components of economic capacity of the enterprise and separate estimates reached effect and efficiency of activity for accounting of an enterprise scale. On the basis of the analysis and synthesis of the existing approaches to an assessment $[1,12,13,14,15$, $18,20,21]$ the choice of significant factors of economic potential and risks of activity of the enterprise, and also a method of their group in the offered model is made. Investment potential is recommended to be estimated by means of indicators of share, labor, managerial, financial, marketing, innovation potentials, effect and efficiency of activity of the enterprise. Investment risks on the basis of indicators of the investment climate, financial, production commercial risks of the enterprise and its goodwill.

The model of an assessment is open - allows addition of indicators of other factors of investment appeal and the parameters essential to specific users characterizing them.

It is offered to calculate level 1 indicators in a formula (1) on the basis of linear factor models $L$ of factors with weight coefficients $C_{2 k}$ :

$$
X_{1}=\sum_{k=1}^{L}\left(C_{2 k} X_{2 k}\right),
$$

where as the defining factors of $X_{2}$ the separate listed components of investment potential of the enterprise and its investment risks representing level 2 considered models act. Indicators of $X_{2}$ are estimated by means of linear factor model on the basis of the $M$ intermediate indicators of $x_{2 j}$ (level 2) characterizing them with weight coefficients of $c_{2 j}$. Intermediate $x_{2 j}$ values also represent linear model on the basis of the given values of the corresponding private indicators of $x_{3 j i}$ (level 3) quantity of $N_{j}$ with weight coefficients of $c_{3 j i}$. As a result equality is carried out: 


$$
X_{2}=\sum_{j=1}^{M}\left(c_{2 j} x_{2 j}\right)=\sum_{j=1}^{M}\left(c_{2 j} \sum_{i=1}^{N_{j}}\left(c_{3 j i} x_{3 j i}\right)\right)
$$

In all specified cases weight coefficients are offered to be determined by the rule of Fishburne [19] providing adoption of the best estimated decisions in conditions when it is not known of the value of $N$ factors anything, except an order of decrease of their importance, and then the importance of $i$ of a factor is defined:

$$
r_{i}=\frac{2(N-i+1)}{(N+1) N}
$$

Use of the coefficients reflecting expert evaluations of the importance of factors for the specific enterprise or the investor is in that specific case allowed. Lack of the fixed weight coefficients allows the end user to add independently to model indicators of level 2 and private indicators of level 3, essential to it (to delete insignificant).

Authors on the basis of the analysis $[1,6,12,16,17$, etc.] the set more than 300 private indicators allowing to carry out an assessment of investment appeal taking into account a set of various factors is selected and reasonable. All private indicators of model (level 3) are given to the comparable range of values $[0 ; 1]$. For quantitative indices reduction formulas are used (for the indicators having direct and retroactive effect on investment appeal of the enterprise, respectively):

$$
x_{3 i}=\frac{a_{i}-a_{i \min }}{a_{i \max }-a_{i \min }}, \quad x_{3 i}=\frac{\left(a_{i \max }-a_{i}\right)}{a_{i \max }-a_{i \min }},
$$

where $a_{i}$ - $i$-value of a private indicator for the considered enterprise; $a_{i m a} x$ and $a_{i m i n}$ - basic $i$-values of a private indicator. Thus for indicators like "risk" of $a_{i}$ the return is defined as size, their probabilistic assessment.

As basic values $a_{\text {imax }}, a_{\text {imin }}$ the maximum and minimum measure values among group of the compared enterprises, or the acceptable levels of an indicator established by the investor can be applied. The second option allows to estimate investment appeal of one enterprise out of group, in the ratio with the certain reference object having the characteristics, the best in the industry demanded by the investor, etc. Value (point) in the range $[0$ is appropriated to qualitative private indexes; 1] according to the criteria established individually for each similar indicator. As a result of value of all indicators of the model $x_{3 i}, x_{2 i}, X_{2 i}, \mathrm{X}_{I P}, X_{I R}$, $Y_{0}$ vary from zero (the worst state) to unit (the best state). Value of integral total of investment appeal $Y$ forms using a correction multiplier of $K$ considering quantity of the private indicators of $x_{3 i}$ used for the specific enterprise:

$$
Y=K Y_{0}
$$

The correction multiplier of $K$ is calculated on the basis of the same model which will be applied to an assessment of an integral indicator of $Y 0$, with preserving of a set of the defining indicators and the chosen values of all weight coefficients. But at calculation of a correction multiplier instead of values of private indicators of $x_{3 i}$ it is substituted 1 if for the considered enterprise value of the corresponding indicator is known and it is used at an assessment; and 0 if it is not used, no.
Then the correction multiplier accepts value from range $[0 ; 1]$ where 1 means the most complete use of information - at an assessment of the enterprise all indicators provided by model are considered. Use of weight coefficients of model at calculation of $K$ allows to consider the importance of absence of specific primary data at an assessment of degree of reliability of aggregate result. Value of integral total of $Y$ allows to estimate investment appeal of the enterprise from 0 (attractiveness is absent) to 1 (maximum level).

The developed economic-mathematical model can be applied as to a choice of the most attractive options of development of the enterprise with forming of the corresponding investment image, and to a choice of potential investees. The organization of the step-by-step choice allowing on a limited set of indicators criteria, critical for the specific investor is for this purpose provided to select from a large number of options of development of the enterprise or according to the applicant enterprises them significantly smaller group for which then to make more detailed analysis of investment appeal. It allows to reduce volumes of the processed primary information, quantity labor-consuming and not always reasonable calculations.

Authors suggest to carry out primary selection of objects on compliance of values of the private indicators of model of an assessment, most important for the specific investor. It will allow to limit the list of objects of the subsequent analysis significantly. At the following stage to be made the main selection of objects as which criteria values of group indicators of $X_{2 i}$ of separate types of investment potential and investment risks of the enterprise act. To each stage there is an increase in volume of the considered information about reasonably the chosen indicators that reduces risk of adoption of the wrong decision by the investor. Thus it should be taken into account situations, first, when applicant object, having some indicators is slightly worse than admissible level, as a result can yield acceptable aggregate integral result. Secondly, when all objects have values of a certain indicator worse than admissible level, then at mutual interest it makes sense to recommend to the investor reduction of requirements. In connection therewith it is offered to create in selection process two lists with the different level of selection: the main, containing objects which all indicators have the values entering the admissible range, and the additional, containing objects which some indicators deviate admissible level for the worse no more than for $15 \%$. Practice of the market shows that accounting of a similar deviation is considered acceptable at accomplishment of procedure of an assessment, but also size can be adjusted in interests of the investor.

The technique implementing author's methodical approach has the following idea.

Step 1. Forming of model of an assessment. The offered model of an assessment has no static structure. Before its use it is necessary to perform a choice of specific characteristics of the varied parameters. It is for this purpose carried out:

1) selection of essential group $X_{2 i}, x_{2 i j}$ and private $x_{3 i j}$ of indicators of model and task of weight 
coefficients of model. At the insignificant importance of factors equal coefficients are applied. If only the order of decrease of the importance of the factors characterizing one indicator is taken into account weight coefficients of Fishburne - a formula (4) are applied.

2) in the presence of the reasonable differentiated preferences concerning the importance of the separate factors reflecting interests of the specific enterprise or the investor they are considered in the corresponding weight coefficients;

3)choice of base of reduction of private quantitative indices: the maximum $a_{\text {imax }}$ and/or the minimum $a_{i m i n}$ of the basic values used in formulas 5 .

4)a choice of criteria of an assessment of the private qualitative indexes providing their reduction to the comparable range of values $[0 ; 1]$.

Step 2. Collection of information, the activity of the enterprises and the assessment reflected in model characterizing internal and external factors in the form of private indicators.

The quantity of the considered private indicators influences aggregate result through the correction multiplier used in a formula of calculations (6) and accepting values in the range $[0 ; 1]$. The higher it value, the is less uncertainty of a situation and risk of receipt of wrong result.

Step 3. Carrying out primary selection (in three stages). At the first stage the assessment of the acceptability of objects of the analysis on 3-4 most critical for the investor to private indicators criteria is performed. At the second stage the acceptability on 7-8 significant private indicators is in addition estimated. At the third stage - in addition 15-18 following on the importance of indicators. The specified quantity is recommended and can be changed according to interests of the investor. If at any stage criteria are not set, pass to the main selection (a step 4). For each stage of primary selection private indicators criteria which acceptability of values is critical for the investor get out. On the basis of the analysis of frequency of use of private indicators of author's model which is carried out in research in different evaluation methods of investment appeal of the enterprise the 10 most used indicators recommended as criteria of primary selection are allocated: coefficients of current liquidity and autonomy and indicator of return on equity for primary selection, and in addition indicators of return on assets, profitability of sales, profitability of the invested capital, absolute liquidity, receivables turnover ratio, a market share and investment appeal of the region for the following selection. This structure of indicators allows to characterize the enterprises for the main results of activity, but it can be and is changed according to requirements of the specific investor.

The choice of admissible levels for indicators criteria of primary selection assumes a task of the lower bound of admissible range of values $a_{i}{ }^{\mathrm{min}}$ for indicators of direct action and the upper bound $a_{i}^{\max }$ for indicators of retroactive effect as which normative values, averages on the industry, or critical for the investor, etc. can be chosen.

Step 4. Carrying out the main selection at which each stage as eligibility criterion of objects one group indicator of the $X_{2 i}$ level 2 acts (a component of investment potential or factors of investment risks). The quantity of stages corresponds to quantity of indicators of $X_{2 i}$ in model. For each group indicator criterion of $X_{2 i}$ admissible level - the lower bound of admissible range of values is set $\left[X_{2 i}{ }^{m i n} ; 1\right]$ as which value, critical for the investor, gets out.

The sequence of carrying out stages of the main selection is defined as reduction of the importance of factors of $X_{2 i}$ for the specific investor, i.e. their weight coefficients in an integral indicator of the $Y_{0}$ model. At an assessment of a group indicator criterion of $X_{2 i}$ of the current stage of selection for the remained objects only private $x_{3 i}$ and intermediate $x_{2 i}$ the indicators relating to the current $X_{2 i}$ are used. It is for this purpose carried out:

1) determination of basic levels of $a_{i m a x}, a_{i m i n}$ of private quantitative indices. In the absence of the acceptable levels set by the investor as basic levels the maximum and minimum measure values among the actual can be used. If use of the minimum basic level of $a_{\text {imin }}$ is not provided in model, it is accepted equal to zero. If the actual value of a private indicator of direct action of $a_{i}$ exceeds the maximum $a_{\text {imax }}$ acceptable level established by the investor as the last $a_{i}$ value is accepted. For indicators of retroactive effect if the actual $a_{i}$ value is lower than the minimum acceptable $a_{\text {imin }}$, it becomes the minimum basic level. Thus basic levels of $a_{\text {imax }}$ and $a_{\text {imin }} i$ of an indicator cannot be equal, differently the denominator is equal in a formula (5) to zero;

2) reduction of the actual $a_{i}$ values of private quantitative indices to a comparable form of $x_{3 i}$ for each object of an assessment on the basis of expressions (5). If the actual measure value of direct action is lower than a basic level of $a_{i m i n}$, or the actual measure value of retroactive effect is higher than $a_{\text {imax }}$, the given $x_{3 i}$ value is considered equal to zero;

3) calculation of a group indicator of $X_{2 i}$ of a stage (making potential or reliability) for each object of an assessment according to expression (3).

Step 5. Measure calculation of $Y$ for the selected objects which remained in lists includes calculation of measure values of potential and risks $\left(X_{I P}, X_{I R}\right)$ - a formula (2), a correction multiplier $(K)$, a final integral indicator of $Y$ - a formula (1) and (6).

Step 6. Ranging of the selected objects as increase in an indicator of $Y$ as a result of which of group of the remained enterprises the object with the maximum complex result of $Y$ can be chosen.

Step 7. The decision concerning the acceptability of result of selection. As a result of accomplishment of all actions will be received or the ranged sequence of the objects meeting requirements of the investor then is carried out transition to a step 8, or the empty list if any of applicants does not conform to requirements, then reduction of requirements of the investor, and repeated carrying out procedure of selection, or an exception of consideration of all current objects and transition to a step 8 is possible.

Step 8. Decision-making. In the ranged sequence the object with the highest value of total of $Y$ possesses the best characteristics and it should be recommended as the 
best object for investment from the considered group. In case of the empty list the conclusion about unacceptability of all applicants is drawn and the issue of selection of the new is resolved.

Steps 1 and 3 of the described technique can be executed by the group of experts number of 8-10 people, as a part of heads of divisions of the enterprise in which interests the assessment is made, and also the involved third-party experts - specialists in the field. Steps $4 \ldots 6$ can be executed by specialists of the corresponding qualification, for example, the staff of the enterprise in which interests the choice and an assessment, or by means of the software product developed by authors with ensuring input of basic data with the operator is made.

\section{Practical importance and results of research}

Unlike known methods of an integral assessment the offered author's methodical approach provides: 1) the organization of step-by-step two-level selection with forming of the main and additional lists at which each stage the list of objects for the subsequent analysis is reasonably limited and the number of labour-consuming or unreasonable calculations decreases; 2) the additional list with other level of criteria for selection of separate indicators allows to consider the selection options attractive by an integral assessment; 3) receipt of the aggregate result corresponding to the interests of the specific user finding reflection in sequence of the analysis of selection criteria, the list of conditions of compliance for each stage of selection, structure of indicators of model and their weight coefficients.

The integral result of an assessment of investment appeal of $Y$ can be used by the investor as a sufficient indicator at a choice of the enterprise investment object or as the additional indicator at an assessment of attractiveness of the investment project characterizing reliability of the enterprise as bases of implementation of the considered project.

On the basis of the offered uniform methodical approach to a choice and an assessment of options by authors the algorithm [22] providing the organization of their step-by-step two-level selection with forming of the main and additional lists in full accordance with the given technique and calculation of a final integral indicator of their investment appeal is developed. Based on algorithm the software product [23] in the form of a web application which application provides automation of the provided calculations of economic-mathematical model, and also input and use only of necessary information on the enterprises that allows to process different options of basic data in acceptable time limits is created.

Practical approbation of the developed methodical approach to a choice and an assessment of industrial enterprises on an indicator of investment appeal is carried out on the example of group of companies of a type of economic activity "Production of radio - and the television transferring equipment" on the basis of the option of implementation of model of an assessment proved by authors, including a choice of weight coefficients and basic levels for reduction of private indicators to a comparable form. In case of availability at the specific investor of other preferences concerning the importance of factors and a choice of basic levels, they can be considered in model that will provide forming of the ranged list of the enterprises corresponding to interests of this investor.

The result of primary selection among group of the analyzed enterprises on the basis of the corresponding forms of the financial reporting for 2015 allowed to carry in the main list Joint-stock company "Yaroslavsky Radiozavod" (YaRZ) and Omskoye Open joint stock company "Radio plant of A.S. Popov" (ORZ), and in the additional list to carry the Public joint stock company "Radiozavod" (PRZ) and Joint-stock company "Ryazansky Radiozavod" (RRZ).

For comparison of options 3 types of investment policy for which weight coefficients of investment potential of $X_{I P}$ and factors of investment risks of $X_{I R}$ had ratios were defined: aggressive type as 0,6667:0,3333, conservative type as $0,3333: 0,6667$, moderate type as $0,5: 0,5$.

In the table results of a complex assessment of the enterprises which passed primary selection on the basis of data of their reporting for 2015 are provided. The assessment is executed for three cases: a priority of the importance of investment potential and aggressive type of the investor $(P>R)$, a priority of the importance of investment reliability and conservative type of the investor $(P<R)$, the equal importance of the specified factors and moderate type of the investor $(P=R)$.

Table 1. Result of an assessment of investment appeal for group of companies.

\begin{tabular}{|c|c|c|c|c|c|}
\hline \multirow{2}{*}{ 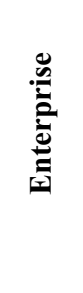 } & \multicolumn{2}{|c|}{$\begin{array}{c}\text { Performance } \\
\text { level } 1\end{array}$} & \multicolumn{3}{|c|}{ Type of investor } \\
\hline & $X_{I P}$ & $X_{I R}$ & 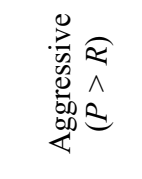 & 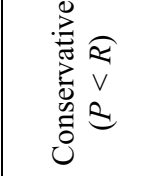 & 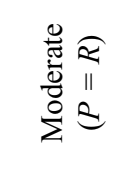 \\
\hline YaRZ & 0.254 & 0.409 & $\begin{array}{l}Y_{0}=0.305 \\
K=0.648 \\
Y=0.198\end{array}$ & $\begin{array}{l}Y_{0}=0.357 \\
K=0.693 \\
Y=0.247\end{array}$ & $\begin{aligned} Y_{0} & =0.331 \\
K & =0.670 \\
Y & =0.222\end{aligned}$ \\
\hline PRZ & 0.410 & 0.231 & $\begin{array}{l}Y_{0}=0.350 \\
K=0.652 \\
Y=0.229\end{array}$ & $\begin{array}{l}Y_{0}=0.291 \\
K=0.691 \\
Y=0.201\end{array}$ & $\begin{aligned} Y_{0} & =0.321 \\
K & =0.671 \\
Y & =0.215\end{aligned}$ \\
\hline ORZ & 0.245 & 0.235 & $\begin{array}{l}Y_{0}=0.242 \\
K=0.621 \\
Y=0.150\end{array}$ & $\begin{array}{l}Y_{0}=0.900 \\
K=0.675 \\
Y=0.161\end{array}$ & $\begin{aligned} Y_{0} & =0.240 \\
K & =0.648 \\
Y & =0.156\end{aligned}$ \\
\hline RRZ & 0.161 & 0.217 & $\begin{aligned} Y_{0} & =0.179 \\
K & =0.639 \\
Y & =0.115\end{aligned}$ & $\begin{aligned} Y_{0} & =0.198 \\
K & =0.684 \\
Y & =0.136\end{aligned}$ & $\begin{aligned} Y_{0} & =0.189 \\
K & =0.662 \\
Y & =0.125\end{aligned}$ \\
\hline
\end{tabular}

According to the maximum values of total of $\mathrm{Y}$ for the investor of aggressive type it is most attractive to investment of Public joint stock company "Radiozavod", to the investor of moderate or conservative type - Joint- 
stock company "Yaroslavsky radiozavod". Dispersion of values of a correction multiplier of $\mathrm{K}$ for all objects and options of an assessment less than 5\% that testifies to use of approximately identical volume of information for each object. It is almost confirmed that the objects which are a part of the additional list of selection can yield high integral result of an assessment (Public joint stock company "Radiozavod").

The offered author's model of an assessment allows to reveal factors which parameter values are critical, and to select from them the most suitable for development of the necessary adjusting managerial actions for the specific enterprise. So the greatest lag of Public joint stock company "Radiozavod" on value of total of $\mathrm{Y}$ is observed in case of conservative type of the investor. In author's implementation of model of an assessment the most essential factor of $\mathrm{X} 2 \mathrm{i}$ is the indicator of financial risks of the enterprise entering model XIR. Decrease in this indicator for Public joint stock company "Radiozavod" will provide decrease in investment risks of the enterprise and it will become the most attractive to investment in the considered group.

\section{Conclusion}

For the purpose of improvement of methodical tools of an assessment of investment appeal of industrial enterprises the economic-mathematical model and methodical approach to a choice of the industrial enterprises conforming to requirements of the investor, and their complex assessment for an integral indicator of investment appeal are offered and proved. It allows to organize the process of a step-by-step two-level choice of investment objects excluding processing of redundant information and which is carried out in full accordance with interests of the specific investor that provides the solution of an actual problem of increase of accuracy of an assessment and allows investors to avoid probable essential economic losses.

The work was supported by Act 211 Government of the Russian Federation, contract № 02.A03.21.0011.

\section{References}

1. V.I. Belotserkovsky, I.V. Streshinsky, and R.A. Rostislavov, News of the Tula state university. Economic and jurisprudence, 3-1, 236-247 (2013)

2. A.V. Bolotin, Positioning of industrial enterprises in the investment market (Chelyabinsk, 2009)

3. O.I. Gavrilyuk, Instrumenty and evaluation methods of investment appeal of industrial enterprises (Belgorod, 2010)

4. V.A. Nikitina, Score of investment appeal of the large Russian companies (Moscow, 2005)

5. M.L. Polumiskov, Development of economicmathematical model and tools of an assessment of investment appeal of the gold mining enterprise (Moscow, 2010)
6. R.A. Rostislavov, Score of investment appeal of industrial enterprise for the strategic investor (Tula, 2011)

7. D.S. Sizyck, Model and methods of an express assessment of investment appeal of the enterprises (Moscow, 2010)

8. E.N. Staroverova, Quality. Innovations. Education, 7, 30-36 (2007)

9. R.A. Brealey, S.C. Myers, and F. Allen., Principles of corporate finance (McGraw-Hill/Irwin, New York, 2010)

10. B.D. Jordan, and T.W. Miller, Fundamentals of investments: valuation and management (McGrawHill/Irwin, New York, 2009)

11. U. Sharp, G. Alexander, and D. Bailey. Investments (Moscow, INFRA-M, 2001)

12. E.V. Bartova, Impact of potential production on increase of productivity of activity of industrial enterprise (Izhevsk, 2011)

13. G.E. Bazhenov, and O.A. Kislitsyna, The Bulletin of the Siberian state space university of the academician M.F. Reshetnev, 3, 176-181 (2010).

14. I.A. Blank, Financial risk management (Nick Center, Kiev, 2005)

15. A.G. Butrin, Z.S. Gelmanova, and D.L. Yaruchin, Metallurgist, 59, 99-103 (2015)

16. V.I. Denisenko, and A.P. Dyachenko, Risk analysis Problems 3, 22-28 (2008)

17. E.M. Korotkov, Bulletin of the Southern Russian state technical university (Novocherkassk polytechnical institute). Social and Economic Sciences series 2, 31-38 (2012)

18. A.A. Tafeeva, Score of investment appeal of the enterprise in the conditions of the innovation development (St. Petersburg, 2011)

19. P. Fishburne, The theory of usefulness for decision making (Science, Moscow, 1978)

20. A.S. Shapkin and V.A. Shapkin, Economic and financial risks. Assessment, management, portfolio of investments (Dashkov and To, Moscow, 2012)

21. A.A. Shaposhnikov, Development of the complex mechanism of the analysis and assessment of investment appeal of the enterprise (N. Novgorod, 2010)

22. M.S. Kuvshinov, A.G. Kalacheva, Algorithm of selection of investment attractive enterprises: Algorithm (South Ural State University (national research University), 50201650127, 2016)

23. M.S. Kuvshinov, A.G. Kalacheva, Calculation of an integral indicator of investment appeal of the enterprises: Program (South Ural State University (national research University), 50201650126, 2016) 